\title{
China's Migrant Workers: How Far from Being Citizens?
}

\author{
Shuya Zhang ${ }^{1} \&$ Guoliang Luo $^{2}$ \\ ${ }^{1}$ School of Humanities and Social Sciences, Beijing Institute of Technology, Beijing, China \\ ${ }^{2}$ School of Economics and Management, North China Electric Power University, Beijing, China \\ Correspondence: Guoliang Luo, School of Economics and Management, North China Electric Power University, \\ Beinong Roud No.2, Changping District, Beijing 102206, China. Tel: 86-136-2108-9944. E-mail: \\ LGL1965@163.com
}

Received: September 27, 2012 Accepted: October 19, 2012 Online Published: December 31, 2012

doi:10.5539/ass.v9n1p171 URL: http://dx.doi.org/10.5539/ass.v9n1p171

\begin{abstract}
Hundreds of millions of farmers have become permanent urban residents. But they do not enjoy the corresponding benefits as citizens. Migration of rural population and labor mobility have become one of the primary elements driving China's economic growth, but migrant workers have to face economic, social, political and cultural challenges and barriers before becoming real citizens. These changes and barriers include unemployment and poverty of landless farmers, labor resource integration, social inclusion and government administration and so on, among which, the reform and improvement of household registration system, land system, labor system and social security system is becoming urgent for the Chinese government. Thus the migrant workers still have a long way to go before obtaining full citizenship.
\end{abstract}

Keywords: farmer, migrant worker, urbanization, citizenization, China

\section{Introduction}

Since the implementation of the opening-up and reform policies of China, the rapid economic development has significantly improved the level of urbanization, with a urbanization rate increase from $22 \%$ to $46.9 \%$, and urban population increase from 254 million to more than 600 million from 1990 to 2009, thanks to the farmers' migration to the urban areas. If the floating population that has lived in urban areas for six months or above is calculated as the "permanent urban residents", the migrant workers (and their families) currently account for one fourth of the total urban population in China. However, they enjoy neither the treatment nor equal rights as the urban residents do. In other words, these migrant workers have not obtained their full citizenship. (Han Jun, 2010)

In view of the economic and social development trend in China, the rapid urbanization in the upcoming 20 years will continue and one of the most primary issues is social adaptability and citizenization. The population changes and labor migration will have significant impact on social development in the synchronous process of industrialization, urbanization and agriculture modernization, among which, the citizenization of migrant workers is an insurmountable major challenge and has become a real concern of the academia and the government.

\section{General Situation of Migrant Workers}

\subsection{Size}

Migrant workers refer to the labor population who register in the rural area but are engaged in non-agricultural work in urban areas, which is a special group in the economic and social transitional period under the special household management system of China. Generally, the term refers to the farmer workers who are not working in their hometown (the farmer workers also include the rural population who are engaged in non-agricultural works in their hometown). Statistically, migrant workers refer to the farmer workers who have worked for six months or above in urban areas other than their hometown (while the local farmer workers refer to those who are engaged in non-agricultural works for at least six months in their hometown).

Since the implementation of opening up and reform policies, the increasing migrant workers have boosted China's urbanization. But the citizenization of migrant workers is rather retarded. The floating population was 6.57 million in 1982 and reached 211 million in 2009. Between 1982 and 2009, the proportion of floating 
population out of the nation's total has increased from $0.6 \%$ to $15.8 \%$. Migrant workers constitute the main part of the floating population and the proportion has increased from $38 \%$ in 1982 to $76 \%$ in 2009 (Table 1).

From 1982 to 2009, the urbanization rate of China has increased by 25.5 points of percentage. Farmer workers swarming into the urban areas has accelerated the process of urbanization and added about 12 points of percentage to China's urbanization rate. Although the size of migrant workers is expanding, the pace of citizenization is retarded. From 1980 to 2008, a total of 270 million people actually changed their status from the agricultural population to the non-agricultural population, but only 20 to 30 million of them have changed their rural household registration to the urban household registration, accounting for only one tenth of the total.

Table 1. Changes of floating population and farmer workers

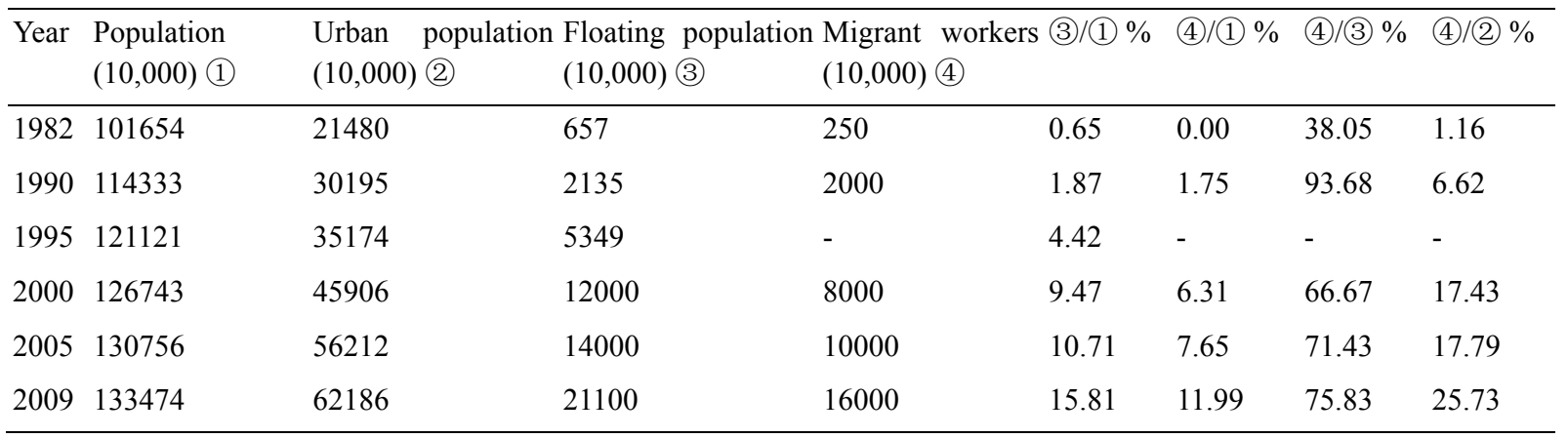

*Source: Study of National Population and Family Planning Commission of China.

\subsection{Basic Features}

The migrant workers are mainly young male, mostly married. From the perspective of gender, men accounts for $65.1 \%$, female $34.9 \%$; from the perspective of age, those aged from 16 to 25 years old accounts for $41.6 \%, 26$ to 30 years old $20 \%$; 31 to 40 years old $22.3 \%$; 40 to 50 years old $11.9 \%$; and $4.2 \%$ for 50 plus; from a perspective of marital status, $56 \%$ of them are married, $41.5 \%$ unmarried and $2.5 \%$ for the rest.

In view of their education background, the majority of migrant workers are those who fulfilled the junior high school education $(64.8 \%)$, the illiterate accounts for $1.1 \%$, those with a primary school education $10.6 \%$, those with a high school education $13.1 \%$, and those trained in the technical secondary school or above account for $10.4 \%$. As high as $51.1 \%$ of the migrant workers receive no skill training in any form. The less education they have, the less training they get. For instance, only $26.3 \%$ of the illiterate and semi-illiterate migrant workers have received skill training, $35.5 \%$ of those with a primary school education, $48 \%$ of those with a junior high school education, while $54.8 \%$ and those with high school education and $62.5 \%$ of those with technical secondary school education have received skill training.

\subsection{Regional Distribution}

In view of the source of migrant workers, most come from eastern China and then central China, with the least from northwestern China, accounting for $44 \%, 31 \%$ and $25 \%$ respectively.

From a perspective of regional distribution of employment, the migrant workers are mainly distributed in the coastal areas, while there has been a rapid increase in the proportion for those working in the central and western China. In 2009, 62.5\% of the migrant workers worked in eastern China, with a decrease of 8.5 points of percentage compared with the figure in the previous year; $17 \%$ worked in the central China, with an increase of 3.8 percentage points while $20.2 \%$ working in western China, 4.8 percentage points higher than that in the previous year. It is noteworthy that more migrant workers are heading for the central and western China instead of the traditionally coastal cities.

Besides, the proportion of migrant workers seeking jobs in their native provinces is on the rise. Among the migrant workers, 74.41 million work outside their native provinces, down $0.6 \%$, accounting for $51.2 \%$ of the total. In contrast, 70.92 million work in their native provinces, up $8.2 \%$ compared with the previous year, accounting for $48.8 \%$ of the total. The proportion of migrant workers working in their native provinces is 2.1 percentage points higher than that in 2008. The increase of migrant workers in 2009 was mainly due to the remarkable increase of migrant worker transfer within the provinces. Most migrant workers in eastern China seek jobs within their native provinces while those from central and western China work in other provinces. However, the proportion of migrant workers from central and western regions seeking jobs within their native provinces has increased considerably. 
The migrant workers mainly swarm to the middle- and large-sized cities above prefecture level. Particularly, the migrant workers working in municipalities account for $9.1 \%$, those in the provincial capital cities account for $19.8 \%$, those in prefecture-level cities $34.4 \%$, those in county-level cities $18.5 \%$, those in townships $13.8 \%$, and others $4.4 \%$. The migrant workers working in the middle- and large-sized cities account for $63.3 \%$ in total.

\subsection{Occupations}

Migrant workers tend to get jobs in the manufacturing, construction and service industries, among which, those working in the manufacturing sector accounts for $39.1 \%$, construction $17.3 \%$, service $11.8 \%$, accommodation and catering industry and wholesale and retailing $7.8 \%$ respectively, while the transportation, storage and postal industry account for $5.9 \%$.

Most migrant workers are working in the form of being employed. Specifically, $93.6 \%$ of them are employed while $6.4 \%$ of them are self-employed, down 0.5 percentage point compared with that in the previous year. The proportions of self-employed migrant workers in the eastern China, central and western China are 5.6\%, 7.9\% and $8.6 \%$ respectively.

\subsection{Incomes and Social Security}

In 2009, the average monthly income of migrant workers was 1,417 yuan. .Those with average monthly income below 600 yuan accounted for $2.1 \%$, those with average monthly income between 600 yuan and 800 yuan accounted for $5.2 \%$, those between 800 yuan and 1,200 yuan $31.5 \%$, those between 1,200 yuan and 1,600 yuan $33.9 \%$, those between 1,600 yuan and 2,400 yuan $19.7 \%$ and those above 2,400 yuan $7.6 \%$.

In recent years, governments on various levels have attached great importance to the wage arrears and established corresponding policies and measures, which have led to significant achievements. In 2009, only $1.8 \%$ of the migrant workers suffered from wage arrears from their employers, 2.3 percentages lower than that in 2008 when it was $4.1 \%$. Most migrant workers suffering from wage arrears were working in the construction and manufacturing sectors.

A survey indicates that migrant workers have longer working time a day and that varies remarkably from sector to sector. Migrant workers worked 26 days a month and 58.4 hours a week on average. Specifically, $89.8 \%$ of the migrant workers worked more than 44 hours a week as stipulated in the Labor Law. Among the main sectors which most migrant workers are engaged in, the average working time of manufacturing sector is 58.2 hours a week, the construction industry is 59.4 hours, the service sector 58.5 hours, the accommodation and catering industry 61.3 hours, and the wholesale and retailing sector 59.6 hours. The accommodation and catering industry has the longest average working hours, more than 60 hours per week.

The proportion of migrant workers who sign labor contracts with their employers is quite low (about $40 \%$ only). In 2009 , only $42.8 \%$ of employed migrant workers signed labor contracts with their employers. The proportion of migrant workers without labor contracts is comparatively high in sectors such as the construction, manufacturing, service, accommodation and catering sector and wholesale and retailing industry with a proportion of $74 \%, 49.3 \%, 63.9 \% 65.2 \%$ and $66 \%$, respectively.

The proportion of migrant workers covered by the social security is low. In 2009, the proportion of those with pension insurance, work-related injury insurance, medical insurance, unemployment insurance and maternity insurance were $7.6 \%, 21.8 \%, 12.2 \%, 3.9 \%$ and $2.3 \%$, respectively. The social security coverage of migrant workers varied greatly from region to region. Generally, the proportion of migrant workers covered by the social security in the central and western China is similar, but much lower than those working in the eastern China.

Moreover, the social security coverage level of migrant workers varied significantly from sector to sector, of which, the manufacturing is relatively better. It is noteworthy that only $15.6 \%$ of employers of the construction sector which features high risks of work-related injury covered the migrant workers against work-related injury, and the proportion of migrant workers covered by pension, medical insurance and unemployment insurance in this sector was much lower, only $1.8 \%, 4.4 \%$ and $1 \%$, respectively.

\section{Why Do Migrant Workers Flow into Urban Areas?}

For those farmers in China who swarm into the urban areas to earn money, they are not completely voluntary but forced to.

\subsection{Going to Urban Areas on Voluntary Basis}

Some farmers voluntarily choose to work in the urban areas to make a change to their lives. During the process of economic and social development in human society, the transformation of social division and economic structure, which result from the growth of social productivity, is primarily responsible for the transfer of labor 
force. Fundamentally, the development of social productivity determines the extent of labor force transfer, i.e. the development of productivity leads to social division, which reinforces labor force transfer. For instance, the three social divisions in the human history, i.e. the separation of nomadic animal husbandry from agriculture, the separation of handicraft industry from agriculture, and the emergence of commerce and merchants, made labor force transfer from agriculture to animal husbandry, handicrafts and commerce, which can be seen as the transfer of labor and changes of farmers' identity. With continuous progress in science and technology and improvement of the productivity, the labor force will continuously transfer from the agriculture to the secondary and the tertiary industries and a growing number of farmers will gain urban citizenship.

The labor force transfer and emergence of migrant workers can be explained from the aspect of "driving force". The implementation of household contract responsibility system has given farmers decision-making power on production and operation, offered possibilities of free flow of farmers and enabled villages to freely choose their future, thus offered an institutional premise for the rural labor force transfer and farmer seeking jobs in urban areas, just as the common understanding of the academia. The re-liberation of farmers enabled by the widely implemented household contract responsibility system revealed the labor surplus, which has long been hidden in the collective labor system and gradually formed a strong potential force in driving the surplus labor from agriculture to non-agricultural businesses, as a result of which, along with the gradual opening-up and loosening of the policies which used to restrict the free flow of rural population and urban-rural relationship, the social migration of farmers, driven by interests, among industries, regions and the rural and the urban areas, is on the rise and creates diversified employment modes. Wide range flow of farmers and diversified profession differentiation accelerated the labor force transfer and the farmers' making inroads into urban areas from rural areas.

It is worth mentioning that the introduction of market system and improvement of market economic system are critical factors accounting for the labor force transfer, which are often ignored by the academia or failed to be seen as an independent element with due attention while discussed together with the household contract responsibility system. Although agricultural management system with the household-contract responsibility system as its core has been dominantly established in the market economy, it only made it possible for labor force to get separated from agriculture. The introduction of market mechanism and establishment and gradual improvement of the market economic system in China provided a broad space for the rural labor force to transfer to the non-agricultural professions and enter urban area.

\subsection{Forced to Work in Urban Areas}

The involuntary migrant workers refer to those who lost the farmland and were forced to seek a job in the urban areas. With rapid urbanization and increasing demand for land in urban areas, tens of millions of farmers are stripped from the farmland and the number is on the rise. Studies suggest that from 1987 to 2001 the non-agricultural construction occupied 33.946 million mu (about 2.263 million hectares) of farmland and at least 35 million farmers lost or reduced their land due to land requisition (Cui Lijin, 2003). Some scholars believed the number of farmers who lost land is much larger because the number released by the Ministry of Land and Resources was calculated based on the construction projects that turn the agricultural land to non-agricultural purpose approved by the State Council, not including the unauthorized land occupation, excessive land occupation and unauthorized land sale in some rural areas. Statistics indicate that illegal occupation accounts for about $20 \%$ to $30 \%$ of the legal land requisition (Duan Yingbi, 2004), which means between 40.80 million (2.72 million hectares) and 44.20 million mu (2.95 million hectares) of farmland were actually occupied from 1987 to 2001, and between 51 million and 55.25 million farmers became landless if the per capita ownership of land is $0.8 \mathrm{mu}$ (about 532.8 square meters) (The actual per capita farmland in the developed area is lower than $0.7 \mathrm{mu}$ or 446.2 square meters). If the laborers who fail to obtain their household registration and are then unable to get the proportional part of farmland because their parents did not abide by the family planning scheme, are included, the number will exceed 60 million (Song Bingwen, 2003).

From a conservative view, at least 50 million farmers became landless by 2001. Given that each year from 2002 to $2009,2.5$ million mu (about 166,666.7 hectares) of farmland was under requisition and the per capita ownership of farmland in the outskirt was $0.7 \mathrm{mu}$, every year the number of landless farmers may rise by 3.5 million and a total of 28 million farmers became landless from 2002 to 2009. By 2009, the landless farmers would have reached 78 million, including the 50 million before 2002, in a conservative estimate.

The most direct impact of being landless on farmers is employment. Most surveys indicate the unemployment rate of landless farmers is about $20 \%$ to $30 \%$, much higher than that in other social groups. Most the landless farmers choose to seek a job in the non-agricultural fields, apart from a small part who are still engaged in 
agriculture (Rural Investigation Team, National Bureau of Statistics, 2004, Li Futian, 2009). However, the data only statically indicate the employment difficulty of landless farmers. To reflect the impact brought by the land requisition more objectively, a dynamic comparison between the situations of the landless farmer before and after the land requisition shall be made. But the studies on this aspect are quite limited. Zhu Dongmei and Fang Gang (2008) found in Chengdu and Dujiangyan, the total unemployment rate and proportion of landless farmers engaged in non-agriculture professions (in hometown or out of the hometown) have increased from $1.8 \%$ and $23.1 \%$ to $26.0 \%$ and $52.2 \%$ respectively, while the proportion of landless farmers engaged in agriculture has plummeted from $72.2 \%$ to $2.4 \%$. In other words, the proportion of farmers engaged in non-agriculture occupations has soared from $23.1 \%$ to $52.2 \%$ after losing their farmland, up 29.1 percentage points. Based on this proportion, 22.7 million landless farmers were forced to be migrant workers in 2009, accounting for about $10 \%$ of the 229.78 million migrant workers in the year, given 78 million farmers becoming landless in the year. If calculated according to the data released by the National Bureau of Statistics, about $63 \%$ of the farmers swarming into urban areas, about 14.3 million landless farmers were forced to be migrant workers.

In other words, farmers who were forced into the urban area after losing their land account for about $10 \%$ of the total migrant workers. Although the proportion is low, the absolute figure is quite big. The current unfair land requisition and compensation mechanism give rise to serious social conflicts with the 14.3 million landless farmers' involuntary flooding into urban areas.

\section{Challenges and Obstacles Confronted by Migrant Workers}

Going to the urban area not only opens a wide space for the farmers'employment and enhances the development of job market, but also function as a driving force for China's system reform and social transformation.

The floating migrant workers have broken the limits of job market between the rural and the urban areas, between the regions and departments, made the market-oriented free-choice of occupation a reality, enhanced the development of China's labor market and labor system reform, accelerated the formation of the labor resource relocation mechanism through market, and undeniably, it has also significantly facilitated the transformation of the government functions and management modes. The huge across-region flooding of farmer workers, has improved vitality and vigor of the entire society and challenged the urban and social management system.

Since China carried out the opening-up and reform policies, the migration of rural population and labor force mobility have become one of the major driving forces for the economic development. However, the migrant workers are faced with economic, social, political and cultural barriers to gain real citizenship.

\subsection{Loss of Farmland and Social Stability}

With acceleration of industrialization and urbanization, there has been a rising demand on land for non-agricultural purpose and it is inevitable for the farmland to be confiscated on a large scale, which will lead to the loss of farmland for non-agricultural purpose on a large scale. For farmers who live on farmlands for generations, loss of farmland means unemployment, loss of economic sources and life guarantee. The landless farmers, as the disadvantaged group, could hardly affect the political decision-making with their own power, nor could they make the public policies protect their interests and rights essentially. As a result, they are gradually excluded and marginalized. The inclement social reality will psychologically induce their risk awareness and generate a sense of deprivation and discontentment, accordingly a series of increasingly serious social problems have arisen, among which, the violent incidents caused by the land confiscation and mass incident are more than often. Therefore, the problem of landless farmer involves not only the economic problems of land confiscation and compensation, but also the social stability and sustainable development, more importantly, the institution.

\subsection{Competition in the Labor Market}

The migrant workers will impact the employment of the original urban residents, which on one hand, can lower the enterprise costs, help expand the production scale and thus create the scale effect, increase job opportunities in urban areas and accordingly the employment opportunities for the original urban residents. On the other hand, especially in a short run, the increase of employment opportunities among some part of people will lead to the decrease of that among another part of people in the same labor market, i.e. migrant worker flood will certainly reduce employment opportunities among the local population, which is the substitution effect in the labor market. At present, the impact is rather limited because of discrimination to migrant workers caused by the household registration system and other factors. But with the acceleration of urban-rural integration and citizenization of migrant workers, the discrimination will fade out, and accordingly the impact of substitution effect might fade in. Therefore, it is a big subject on how to tackle with such an impact. 


\subsection{Social and Cultural Integration}

Theoretically, in a market economy, promoting the urbanization process will help eliminate the urban-rural dualistic structure. However, as urban construction is often given priority in the urbanization process, the urban and rural system reform could not get enough attention, and the dualistic structure has not been changed. The barriers between the urban and the rural areas are still rigid among which, not only the migrant workers could hardly find a job in urban areas, but also the advanced productivity and culture could not be transmitted to rural areas. Accordingly, a new dualistic structure is formed in the urban area, which reflects the significant differences between the migrant workers and the local residents with their household registered. Although these migrant workers become industrial workers in urban areas, they cannot change their identity as farmers, and have to be confronted with serious unfair treatment in terms of incomes and social security, and become the disadvantaged and marginalized group with the least social security in urban areas.

The new dualistic structure in the urban area gives rise to the barriers in the integration between migrant workers and the local residents with their household registered in the urban area. From the aspect of migrant workers, they have shown some adaptation to the urban life and have a strong desire to integrate into the urban life, hoping to become a member of urban areas. In reality, although residents with their household registered locally rationally tend to accept the migrant workers, they are not really willing to have any contact with migrant workers, they have no interest in migrant workers and even do not wish their children to socialize with children of the migrant workers, which reflects that some citizens still have a repulse psychology, because of the inadequate qualifications of migrant workers, the inherent superiority of urban residents formed in history and the estrangement caused by lack of understanding about migrant workers.

As a result, the social integration of migrant workers is becoming increasingly urgent with the urban-rural integration and citizenization, which is also a major challenge to the urban management.

\subsection{Lagged Urban Management and System}

Under the traditional planned economy system, the society was managed in the mode of urban and rural division. The management system of urban government was mainly established according to the scale and distribution of the urban registered population. Since the reform and opening-up policies of China were put into practice, the population migration, especially the labor population migration across regions and between the rural and urban areas, has been on the rise. Great changes have taken place in the structures of urban labor force and residents in the eastern developed urban areas, in some of which, there has been a flow of migrant farmer worker population, which is even larger than the locally registered population. Compared with the original urban registered people, the migrant workers make equally great contribution to the urban development by creating a large amount of wealth and paying taxes. However, they cannot enjoy the treatment as urban residents in terms of public facilities and services, since they are not covered by the urban household registration system. As a result, a pattern of "one city, two systems" arises, the primary cause of which is that the urban management system features vertical administrative arrangement, which attracts a great number of high-quality resources flowing into the topmost cities. Therefore, a distorted pattern is formed up: large cities are getting increasingly prosperous and set up many barriers to restrict the entry of vehicles and population. In addition, there is a strict administrative division between cities, in case of which, each city would like to obtain scarce resources, such as land and capital, as much as possible. They want migrant workers to work for them and build the cities but do not want to cover the cost for public services or social security.

The migrant workers' participation in the political and social activities in the cities is inadequate. Most migrant workers are willing to give up neither their contracted plots of land, forest and grassland in rural areas nor their homestead for urban household registration. In real terms, the current Chinese migrant workers are not urban residents, so they are not significant for the change of the Chinese industrial structure and the adjustment of the relations between urbanization and industrialization.

\subsection{Obstacles from Household Registration}

First, the household registration system results in inequality in social status. The core task of the household registration system is to divide the households into two categories, namely the agricultural households and the non-agricultural households, and link the household registration with different rights and interests. Therefore, people with different household registrations enjoy different rights and interests, and this is inherited by blood lineage, which contradicts with human equality. Second, the household registration system causes inharmonious development that has been existing between the rural and urban areas for a long time. It brings obstacles for regular population migration between cities and towns. The strict limits on "migration from rural area to urban area" and "transformation from rural residents to urban residents" have established barriers for the transfer of 
rural surplus laborers to other places, seriously affecting the urbanization of China. This is contradictory to the rapid urbanization and modernization of China. Third, the household registration cannot provide accurate population statistics. The household registration is losing its capability to serve as a regular tool for obtaining accurate population statistics. This is due to the appearance of a great part of population without registration. In some cities and towns, the registered population only account for $70-80 \%$ of the actual permanent resident population. Therefore, there is a lack of reliability in economic statistics based on household registration. Fourth, there is a lack of reliability in urban management based on household registration. Currently, the registered population is often used as a basis for carrying out macro-control of the urban population and management, which results in "ineffective" management to a certain extent. Many large cities have accomplished considerable achievements with a zero growth or negative growth in family planning in terms of the registered population. However, the actual population of which is still growing and family planning among the floating population is not actually enforced.

The reform of household registration is imperative, yet the implementation of which is hard. First, the system is still an effective tool for current social management, which is still used as the standard for distributing regional public resources in management by administrative divisions, such as the college student recruiting. Second, the great gap between the rural and urban areas indicates that an aggressive reform and even the simple cancellation of the household registration system may cause tremendous social risks. As big cities are extremely attractive to rural population, to a certain extent, the household registration system can ease up the threat from the floating population to cities so that China can avoid the risks of excessive urbanization and urban pauperization that have been experienced by the developing countries in South America and South Asia. Third, in the contemporary society with urbanism playing a leading role, the reform of household registration also encounters the impediment from the urban dominant social stratum with rights to speak.

\subsection{Other Social Problems}

In recent years, both the central and local governments have made great efforts in serving the migrant workers, whose work and living conditions have been greatly improved. However, there are still many problems.

First, there are still problems in salary, treatment and working conditions. Generally, migrant workers are among the low-paid group; back pay still exists, which has become a distinctive problem in distribution. In addition, there are poor work security and sanitary conditions, which lack the basic labor protection. It is common that farmer workers work overtime and overload without any guarantee for taking a rest. Besides, farmer workers also fail to enjoy the equal rights for obtaining a job and enjoying public services.

Second, farmer workers' social security benefits are usually insufficient. The arrangement of the current urban social security system and the difference in awareness of the urban governments and enterprises make it hard for farmer workers to enjoy the basic living allowances.

Third, farmer workers rarely enjoy the public services from the urban governments, such as difficulties in receiving compulsory education for their children, farmer workers living in poor housing conditions and the unavailability in public health services.

Fourth, it is hard to for farmer workers to safeguard their legal rights. Unsound laws and regulations make it hard for farmers to exercise their democratic rights; the personal rights of these people are often violated.

Those are problems concerning the labor employment system, social security system and education system. It is of great significance to seek for comprehensive solutions to these issues.

\section{Conclusion}

Farmer worker obtaining citizenship means that farmers work and live in cities and become new members of cities and gradually become integrated into the cities, with not merely the transformation in farmers' occupation, but conversion from traditional rural culture to modern urban culture, which does not simply mean the change in household registration but an assurance that farmer workers can enjoy the same rights in terms of employment, housing, pension, medical treatment and education as the urban residents, and which is related to both the capacity of the cities to provide non-agricultural jobs and the financial power of the cities to provide public services and social security. A series of restrictions are faced to turn the Chinese farmers into urban residents, including the reform of employment, compulsory education, public housing, social security and household registration system. There is still a long way to go to turn the farmer workers that work and live in urban areas into urban residents, to gradually unify the identification of migrant workers and urban residents and enable migrant workers to enjoy equal rights with their urban counterparts. 


\section{References}

Cooper, S. P., Burau, K. E., Frankowski, R., Shipp, E. M., Del Junco, D. J., Whitworth, R. E., ... Hanis, C. L. (2006). A Cohort Study of Injuries in Migrant Farm Worker Families in South Texas. Annals of Epidemiology, 16(4), 313-320. http://dx.doi.org/10.1016/j.annepidem.2005.04.004

Griffin, J., \& Soskolne, V. (2003). Psychological distress among Thai migrant workers in Israel. Social Science \& Medicine, 57(5), 769-774. http://dx.doi.org/10.1016/S0277-9536(02)00447-1

Gu, S. Z., Zheng, L. Y., \& Yi, S. C. (2007). Problems of Rural Migrant Workers and Policies in the New Period of Urbanization. China Population, Resources and Environment, 17(1), 1-6. http://dx.doi.org/10.1016/S1872-583X(07)60001-1

Janta, H., Ladkin, A., Brown, L., \& Lugosi, P. (2001). Employment experiences of Polish migrant workers in the UK hospitality sector. Tourism Management, 32(5), 1006-1019. http://dx.doi.org/10.1016/j.tourman.2010.08.013

Jian, X. H., \& Kun, H. (2007). Up-to-date Investigation Report on Rural Migrant Workers in China. China Population, Resources and Environment, 17(6), 1-6. http://dx.doi.org/10.1016/S1872-583X(08)60009-1

Qiu, P. Y., Caine, E., Yang, Y., Chen, Q., Li, J., \& Ma, X. (2011). Depression and associated factors in internal migrant workers in China. Journal of Affective Disorders, 134(1-3), 198-207. http://dx.doi.org/10.1016/j.jad.2011.05.043

Wang, B., Li, X. M., Stanton, B., \& Fang, X. Y. (2010). The influence of social stigma and discriminatory experience on psychological distress and quality of life among rural-to-urban migrants in China. Social Science \& Medicine, 71(1), 84-92. http://dx.doi.org/10.1016/j.socscimed.2010.03.021

Wang, C. Y. (2011). The Study on Social Integration Status of Migrant Workers and Countermeasures. Energy Procedia, (5), 2082-2086.

Wang, L., Ma, Q. G., Song, Z. F., Shi, Y. S., Wang, Y., \& Pfotenhauer, L. (2011). N400 and the activation of prejudice against rural migrant workers in China. Brain Research, 1375(23), 103-110. http://dx.doi.org/10.1016/j.brainres.2010.12.021

Zhang, H. F. (2010). The Hukou system's constraints on migrant workers' job mobility in Chinese cities. China Economic Review, 21(1), 51-64. http://dx.doi.org/10.1016/j.chieco.2009.10.002 